\title{
Challenges of Principal Succession - Examining the Challenges of Hiring Internal vs. External Candidates
}

\author{
By Lou L. Sabina* \\ Chris Colwell ${ }^{\dagger}$
}

\begin{abstract}
As school districts face shortages of well-qualified and willing candidates to assume the role of school principal, the development of internal succession planning programs, along with the strategic use of external hires for school leadership positions is becoming more common. Based on a multi-year study of five (5) Central Florida school districts, this paper examines the benefits and tensions that district level administrator's face when selecting internal or external candidates for school based administrative positions. We begin with a brief review of the literature regarding internal vs. external hiring. Data from the field is examined thorough the lens of the intersection between the theoretical perspectives of Systems Theory and Person-Environment Fit Theory. Detailed descriptions of findings from the analysis of twenty-one interviews conducted in two of the most active districts involved in formal succession planning work is included along with identified challenges associated with internal vs. external hiring, including resentment from internal candidates when external hires occur, district administration willingness to hire externally, and the challenges associated with recognizing and understanding the culture and climate of a district as an external hire. Opportunities for district leaders are also presented including an examination of the values of new practices that come with external hires, external candidate perspectives on the existing climate and culture of the district or school, and building new networks associated with external hires. Finally, future implications for school districts and universities who prepare school leaders are discussed.
\end{abstract}

Keywords: external candidates, leadership, organizational theory, principalship, succession planning.

\section{Introduction}

School districts across the United States are either currently experiencing or facing a shortage of qualified and willing candidates to assume the role of building principal (Duke, 1988; McAdams, 1998; Papa, Lankford, \& Wyckoff, 2002; Pijanowski, Hewitt, \& Brady, 2009; Roza, 2003; Russell \& Sabina, 2014). Because of this, many school districts have begun to deliberately plan for impending shortages of school-based administrators by beginning in-district programs to recruit and train new leaders to lead their schools. These programs, commonly described as "internal succession planning programs," operate in many forms, with some programs partnering with university preparation programs or

${ }^{*}$ Visiting Assistant Professor, Stetson University, USA.

${ }^{\dagger}$ Associate Professor \& Department Chairperson, Stetson University, USA. 
some handling their preparation internally (Augustine, Gonzalez, Ikemoto, Russell, \& Zellman, 2009).

However, what happens when external school-based administrative candidates wish to become administrators in a district that is participating in internal succession planning? Will they face challenges competing for positions that others have been groomed for? Once hired, will they be either treated differently or unable to fit within the culture of their new school district? Or even more striking, will the district suffer because of failure to integrate out-of-district ideas in their preparation of school leaders? Some (Russell \& Sabina, 2014) have identified this challenge as a major barrier to leadership preparation, which may end up being an "unintended consequence" of a dedicated effort to internally prepare leaders to assume in-district administrative positions.

This paper examines this tension through the presentation of qualitative data gathered from a multi-year study of five school districts in Central Florida. This particular paper examines two of the five school districts, each of which experienced admitted tensions from the recruitment, selection, and retention of qualified school-based administrative candidates. The objective of this paper is to examine those tensions, provide examples of successful and unsuccessful internal and external hires of school-based administrators, and discuss considerations for both districts and candidates debating the selection of an internal or external candidate. It is our hope that our work will inform school-based practitioners, central administrators, policymakers, and educational leadership faculty of the challenges and opportunities associated with the recruitment and eventual hiring of external candidates for school-based administrator positions, in lieu of the internal efforts of the establishment of internal succession planning programs.

\section{Overview of Study}

Data gathered from this study comes from a larger, multi-year study, which began in 2015, and is still on-going. This study examined the deliberate succession planning practices in five different county-based school districts in Central Florida (assigned pseudonyms of Gemini, Rougarou, Valravn, Gatekeeper, and Maverick). Data collected focuses on the larger, overarching systems planning involved in succession planning; interviewing central administrators, program coordinators, building principals, and aspiring administrators throughout each county. Two counties, Maverick and Valravn, are addressed in this paper, as at the time of publication, interviews had concluded with all stakeholders (central administrators, program directors, current building principals, current assistant principals, and aspiring school-based administrators) and data had been synthesized. In addition, these two counties were early adopters of the succession planning process, beginning their deliberate, identified practice of succession planning in January 2015 (Valravn) and August 2015 (Maverick). The other three counties were later adopters (Gatekeeper - May 2016; Rougarou - May 2017; Gemini - August 2017), and thus data has not been fully collected, analysed, and synthesised. In many ways, both Maverick and Valravn served as exemplars in which the other Central Florida districts could adapt and design their programs around their 
successes and challenges. This particular paper is focused on one of the findings from that study, which was identified as a primary tension of succession planning - balancing internal vs. external candidates to recruit and retain talented building leaders for schools.

\section{Research Questions}

The following research questions guide this study:

1. Are there specific considerations that central administration makes when selecting internal or external candidates for school-based administrator positions? If so, what impact do those considerations have on the candidate ultimately selected for a position?

2. What challenges do externally selected school-based administrators identify as existing in their roles?

3. What specific systems can be put in place to balance the tension between external and internal hires for school-based administrative positions? And, how can central administration support newly hired external candidates unfamiliar with the culture and practice of their new school districts?

To answer these questions, we present the findings from each district separately, and then utilize within case and cross-case analysis (Miles \& Huberman, 1994) to compare and contrast each case within their organization. As each county's program is unique, examining each county's challenge separately prior to cross-case analysis is critical to provide fidelity.

\section{Literature Review}

The debate of internal vs. external hires for school-based administrators has not been extensively explored in educational research, however, the issue of whether to hire an individual externally or recruit from within for organizational advancement has been dissected in both economics and management literature. Literature involving external recruitment emerged as the labour market evolved from career workers within an organization to more individualism and willingness to jump companies for advancement. Kanter (1989) was among the first to note that, "climbing the career ladder is being replaced by hopping from job to job" ( $p$. 299). This concept of job hopping may be viewed as a generational shift in workplace loyalty, as a recent report published by CNBC noted that the average tenure of a millennial in a professional, white-collar position is around two years (Dowdy, 2015). This has led to a trend in human resources of focusing on employee attrition rather than employee retention (Burgess, 2016). This societal shift in willingness to change organizations for better salary or career advancement is documented in many business organizations, however, it is not clear as to whether or not this trend is evident in the education sector.

Another perspective on internal vs. external recruitment prevalent in the 
management literature that may correlate with education is the idea that external recruitment keeps internal candidates sharp and committed to their job functions (Chan, 1996; Chen, 2005). In fact, Chen (2005) found that, "although external recruitment hurts the 'morale' of insiders and reduces their total effort, the output of the workers will actually increase" (p. 261). Because education is a profession where there are traditionally more leadership positions at the site-based, school building level than at the district or central administration level, this phenomenon may serve as both a way for external candidates to demonstrate leadership abilities in multiple organizations and for internal candidates to be kept alert and productive. When assessing worker productivity when faced with external candidates, Chen (2005) cited Prisoner's Dilemma Theory as a potential consequence of only internal recruitment, as middle-line managers may be more likely to collude and not demonstrate as much productivity if they face no external pressures.

Educational research literature did not address the challenge of internal promotion vs. external recruitment of school principals until an impending shortage of school-based administrators was projected roughly twenty years ago. Many (Duke, 1988; McAdams, 1998; Papa, Lankford, \& Wyckoff, 2002; Pijanowski, Hewitt, \& Brady, 2009; Roza, 2003; Russell \& Sabina, 2014) have noted job desirability and the increasing challenges of school-based administration as a reason for individuals not seeking internal promotion. Thus, when a shortage exists, alternate forms of recruitment, such as the recruitment of individuals outside of district or county is necessary to find individuals willing to assume the role of school-based administrator. Winter, Rinehart, and Munoz (2002) were among the first to examine external recruitment as a mechanism to fill potential school-based administrative vacancies, noting the lack of qualified candidates with aspirations of school-based administrative positions. Normore (2004) argued that, "If there are enough qualified candidates internally, external recruitment may not be needed" (p. 3).

Despite the limited literature in education and the growing literature base in the economics, management, and public policy sector, one consistent message is clear; external recruitment of leaders does have an impact on internal job satisfaction (Moser, 2005; Silva, 2006). For qualified individuals that were passed over internally in favor of an external candidate, this, in fact, may cause them to become external candidates for another organization. When addressing internal succession planning, this becomes a critical consideration as to whether or not to invest time, energy, and resources into aspiring leaders who may not eventually obtain their desired position.

\section{Theoretical Perspectives}

This study uses a combination of two popular theoretical perspectives common across the management literature; systems theory and person-environment fit theory. Both systems theory and person-environment fit theory offer insight on the appropriate selection of candidates, however, it is the intersection of the theories that addresses the important considerations of external and internal 
candidate selection.

Systems theory. Systems theory offers a unique perspective on schools as organizations. Meyer and Rowan (1977) referred to schools as a rationalized formal structure because of the relational networks created throughout the organization, which in this case, is the school district or county. Weick (1976) referred to individual schools as loosely coupled systems, as the school itself is a smaller system working with in the context of a larger, more complex system. School districts as a whole are considered to be more formal and ordered in their management approach. On most instances, school districts use top-down management from central-administration to set the tone for the leadership and approaches at each individual school building. This could classify school systems as more highly ordered than other organizations. Schneider and Somers (2006) argue that, "Highly ordered systems are too rigid to coordinate new behaviors and likewise tend to fail. Many elements of highly ordered systems are frozen, so that virtually all forces yield, at most, only minor system changes, resulting in too much buffering and low adaptability and evolutability"(p. 355). If school districts are considered to be highly ordered, this would favor internal candidates who have been a part of the system and understand its interworking, and thus would be more willing to adapt to any changes from central administration without hesitation.

Person-environment fit theory. Equally important is the concept of personenvironment fit theory, a staple organizational theory in management literature, especially when assessing middle management, which school-based administrators are traditionally considered. Person-environment fit theory has been used in educational literature for over fifty years, specifically in assessing the job strain for individuals who do not fit within their organizations (Caplan, 1987; Dollard \& Metzer, 1999; Edwards, Caplan, \& Van Harrison, 1998; French, Rogers, \& Cobb, 1974; LaRocco, House, \& French Jr., 1980). Ostroff \& Rothausen (1997) attest that, "underlying the person-environment fit concept is the assumption that individuals will be more satisfied and perform better, and that organizations will be more effective, when attributes of the person and situation match or are congruent" (p. 173). Sabina (2014) comments that, "Selection is the most important element of this theory, as it is the responsibility of an occupation's managers and staffing departments to select individuals who display characteristics that match the needs of the organization" (p. 68). For school-based administrators to be successful, they must meet the demands of multiple stakeholders, including their superiors in central administration and also their subordinates, who are the faculty and staff in their school building. Therefore, selecting individuals that fit within the confines of the organization becomes a critical component of school-based administrator selection.

Intersectionality of theories. The intersectionality of systems theory and person-environment fit theory creates its own unique perspective in assessing internal vs. external recruitment. Person-environment fit theory considers both how the employee fits within an organization and how an organization fits the needs of an employee. However, because school districts may be considered highly ordered systems, selection is a vital piece of the success that each individual school will attain. With high-stakes accountability as a major driver for school 
districts to select the best possible candidates, central administrators may opt to select someone that fits within the structure of their system, possibly an internal candidate already familiar with how the school district operates and who will not require additional training or mentoring. Or, it is possible that central administration will seek individuals who have exhibited success in other organizations and who they believe could fit within their already established system.

Additionally, school-based administrator selection is considered to be one of the most significant events in the life of a school building and organization (Fauske \& Ogawa, 1987). An incorrect selection of a person that does not fit within the system could prohibit school improvement or cause legitimate detachment with the faculty and staff at that school building. Because of this challenge, central administration may find themselves at the crossroads when deciding whether or not to go for an internal candidate already familiar with the environment and the system and also capable of being mentored as opposed to an external candidate who may be an unknown commodity to the system and ultimately may not fit the with the organizational needs of the school district.

\section{Methodology}

Data for this study was collected in Florida, one of fifty states in the United States of America. Florida is a unique state in that its schools are divided into districts based on county lines, creating 67 different county school districts, each with a unique superintendent. The data sources for this sub-study of the larger succession planning study were four different stakeholder groups across both the Maverick and Valravn County School Districts. Four different protocol were used depending on the respondent's role, which were superintendents $(n=2)$, central administrators involved in the program $(n=7)$, and outside-of-county schoolbased administrative hires $(n=11)$. In addition, one aspiring administrator from the Gemini County School District (not addressed in this study) was participating in the Valravn County School District program, as she was seeking a position in Valravn, and not Gemini, her current county school district. Her responses as an aspiring administrator $(\mathrm{n}=1)$ are also included as a part of this study. Therefore, the total stakeholder interviews included in this study were $n=21$. Interview lengths of these 21 stakeholders ranged from 22 minutes and 42 seconds up to 1 hour, 12 minutes, and 4 seconds, of which anywhere from 15-17 questions were directed towards respondents.

Only one question in the protocol directly addressed the internal vs. external selection considerations, however, in some instances, respondents acknowledged this tension prior to this particular question being discussed, or expanded upon this tension following the particular question in the protocol.

Superintendent $(n=2)$ and central administrators $(n=7)$ were asked the following question as a part of their interviews - "What is your opinion on hiring administrators outside of this county? Can you tell us about one positive experience with a hire and one negative experience with a hire?" 
Currently practicing outside of county school district hires $(n=9)$ were asked three questions concerning their experiences entering a new county and being externally hired - (1) "What attracted you to want to be an administrator in this particular county? How does this county compare to the previous county in which you were employed? (2) "Can you provide us with examples of concepts that you "brought in" to this county and how central administration, other principals, and your teachers have received those concepts? Do you think you have helped to advance this district in continuous improvement with those reform initiatives?" and (3) Talk a little bit about your relationships with the teachers in your building? How do you think it has helped (or hurt) you not coming from outside the county and entering an administrative position?"

As one aspiring administrator candidate was permitted to participate in an "internal succession planning program" as an employee of another county, her circumstances are considerably unique, and thus, a specific protocol with targeted questions were not established prior to her interview. However, the open-ended structure utilizing a semi-structured protocol allowed for customizable questions based on her experiences as a teacher in the Gemini County School District, and as a participant in the Valravn County School District's internal succession planning program. Because her experiences are considerably unique, her responses are included as a part of this study.

Interviews were mostly conducted at the central administrative office for each school district or at the interviewees designated school. In two instances, phone interviews were conducted, due to scheduling restrictions. Interviews took place beginning in August 2015 and concluded in October 2016. Data analysis employed within case and cross case analysis (Miles \& Huberman, 1994) and qualitative comparative case study design (Stake, 1995; Yin, 1994). Each district was assessed separately first, and comparisons across districts were then made. Purposeful sampling was used to gather data from "information-rich cases for study in depth" (Patton, 2002, p. 230).

Data were analyzed from the 21 interviews and then were thematically coded (Strauss \& Corbin, 1998). The first author transcribed all interviews themselves, to allow for no discrepancies in interpretation. Interviews were then uploaded into Dedoose, a Qualitative Coding Software, and results were coded first by participant type (superintendent, central administrator, internally selected schoolbased administrator, externally selected school-based administrator, aspiring administrator) and then were sub-coded based on the meaning that emerged. Axial coding was used to identify relationships among codes and to develop coherent categories among the minor themes that emerged. From the data, the theme of internal vs. external candidates emerged as a possible tension in district/countybased succession planning programs. Therefore, the data specifically linked to this theme was assessed more closely, considering key words associated with this tension. As this tension was an identified tension from the larger study, a separate literature review and theoretical framework were constructed in support of this specific consideration. 


\section{Limitations}

Several limitations exist for this study. First, it should be noted that the two county school districts addressed in this paper are considered to be early adopters (Rogers, 1962) of the design and implementation of their internal succession planning programs. Because these two county school districts are early adopters, they did not have the opportunity to fully refine their program, and were in the process of making program adjustments over the period in which the interviews were conducted. Second, while both superintendents and all central administrators were interviewed from both county school districts, snowball sampling was used through identification of externally hired school-based administrators from the superintendents and members of central administrators. Although both county school district websites were scrutinized by both investigators to determine any additional school-based administrators who may fit this particular subgroup, the investigators relied on the recommendations from the superintendents and members of central administration for selection of stakeholders hired externally. The possibility exists that some external school-based administrator hires were not included as part of this study. Finally, the internal succession planning programs take place in county school districts in Central Florida. As school districts in the state of Florida are established by counties, county school districts are naturally larger than other school districts across the United States. The size of these districts enable the capacity to create large-tier funded programs for internal succession planning; programs which may not have the funding outside of these larger districts.

\section{Results}

\section{Maverick County School District - Target Hires Specifically for Positions}

Maverick County School District was unique in their approach to schoolbased administrator selection, based on their recent history and rapidly changing demographics. In early 2000, Maverick County was considered one of the most rapidly growing counties not only in Florida, but in the entire United States. The county had expanded to a point where it was estimated that its population would double, and school facilities were constructed and renovated to account for this population growth. However, the housing crash of 2008 left many unoccupied properties and school districts not even remotely close to capacity. School sites were closed, and consolidation was necessary. Initially, the Maverick County School District did not need to hire school-based administrators, as consolidation had moved many sitting administrators into other roles and vacancies did not often occur. Because of this, the district did not openly recruit individuals for schoolbased administrator positions until 2014, when the then-serving superintendent decided to create a new central administrative role, a "Deputy Superintendent and Executive Director of Leadership Development." The individual in this position was responsible for the recruitment, training, retention, and selection of school- 
based administrators. As there was not much of a need for school-based administrators due to the housing market crash of 2008, when a school-based administrative position opened in this district, the district would normally recruit externally and offer lucrative compensation packages to get qualified school-based administrators to come to the Maverick County School District. Because external recruitment was the common practice, Maverick County School District did not have that deep of an internal pool of qualified candidates for positions. Now faced with the task of internal recruitment, the Deputy Superintendent and Executive Director of Leadership Development decided to design a specific set of competencies and questions to determine whether or not they fit the needs of the district. He commented,

We do not have the pool, the depth chart, so, to start off with, it's the selection of our employees in the district. Every employee in the district. We have established a set of competencies and questions that we're looking for, for a 'Maverick' Fit. And every employee gets interviewed, every employee, they're asked these top 10, 15 competency questions. What we're looking for in an employee. And through that process, we're constantly identifying those future leaders, either instructional leaders in the classroom, leaders in the support system, and future administrative leaders.

Once candidates are identified, the Deputy Superintendent and Executive Director of Leadership Development helps those individuals to determine which roles are best suited for them within the school district, and customizes professional development and training around their needs. When asked about his perspective on internal hires, he noted that he would prefer to hire in house, and only go outside of the county if necessary.

The district superintendent also felt similarly and expressed the importance of hiring school-based administrators from the internal pool of candidates. When asked to comment on external hires, the Superintendent of Maverick County School District was not pleased, and noted that, "two out of the last three principals came from out of county, which is a problem." Additionally, he remarked that the new leadership development model was designed so that the majority of future school-based administrators would be in-house and already accustomed to the "Maverick Way."

As part of this work, both interviewers had the opportunity to interview both of the two above-mentioned "external hires" and asked them for their reasoning of coming to the Maverick County School District and their experiences. Paul Strowman had recently come over to Maverick County School District from the Gemini County School District as an assistant principal. He had served for nine years as an assistant high school principal in Gemini County and had aspirations of eventually becoming a building principal for Gemini County. After applying for multiple positions in Gemini County, Strowman realized that he may have better luck becoming a building principal outside of the county. In an informal conversation with the Maverick County superintendent (then assistant superintendent), Strowman was told that under no circumstances would he be 
considered for a principal position unless he was willing to serve as an assistant principal for a minimum of one school year to learn the culture of the school district. When reflecting on this conversation, he noted that the current superintendent said, "what I need you to do is come and give me a couple of years as an assistant principal, and then we will promote you from that way, so it gave me a feel of the, of the community, and the community of me, and, that's how it kind of happened." After one year of serving as a middle school assistant principal and then one year of serving high school assistant principal, Strowman was moved to be a building principal at an elementary school. When asked about the challenges of being a principal with external administrative experience, Strowman commented, "And most of these teachers, when I first got here, I was at the middle school, so, I have a lot of these teacher's children, then I went over to the high school again, with some of the teachers, and so, it was, hey, this, who's this Dr. S. guy? We hear a lot about them. He's out there, he's visible in the community, so it, my transition was very easy."

Jeff Castignoli was the other recent external hire, who had transitioned from serving as an elementary principal (also in Gemini County) to a new high school principal position in the Maverick County School District. Castignoli had served as an assistant principal in Gemini at both the high school and middle school level for twelve years, and finally was promoted to a principalship, however, he was promoted to an elementary principalship. Castignoli was initially happy to be an elementary school principal for the Gemini County School District; however, his ultimate goal was to become a secondary school principal. After six years of serving in this role, he approached the superintendent and area superintendent about an opportunity to become a high school principal in Gemini County when a position opened up. He described that conversation as follows:

I had the conversation with Dr. Owens who was the prior superintendent before the current superintendent, I had that conversation with her, um, the summer of 2014, um, and, and, um, I brought it up to her, I met with her personally, and then, she said that we'll talk about it again, and mid-year, and that's, you know, when other things started happening at that time. But in the interim, I was talking to the area superintendent about my desires and how I was getting beat down.

Eventually, Castignoli realized that he "would not be considered for the high school vacancy" and decided to begin applying externally, which was what brought him to the Maverick County School District. At the time of the interview, Castignoli had only been in his position for two months, but described his early sense of Maverick as a district in which he would have autonomy over day-to-day operations of his building. He stated:

Things are different in terms of how the day-to-day operations go, in terms of, I mean, you know, we do our own budget here, every school-based has as a budget, but I feel as a school-based principal, I have the autonomy to make decisions and if I have an issue that I need assistance with, I can go directly to 
the person who could make a decision.

Despite Castignoli's positive outlook on his new position, his hire was not met with great levels of confidence from central administration. Charlotte James, the Executive Director of Teaching and Learning admitted to not supporting Castignoli's hire initially. James noted that she supported an internal candidate, and did not believe Castignoli would fare well in the position. When asked to describe her perceptions, she shared a story of Castignoli's hiring process:

when he was hired, I was on the committee, I did not vote in favor of hiring him, I just didn't think he was the right choice, I was concerned that he didn't have, he had a lot of, um, he could develop a school culture and, focus on students, and teachers, and, but, personally, I'm an academic, I was concerned about the academic piece of it. So it just didn't feel as that was the right decision, and because he was from outside the county, I didn't have anyone to bounce that idea, I, I couldn't ask anyone that question. He's been here now for a month or so. I think, I'm going to be proven completely wrong, which I'm fine with, because in my dealings with him now, I realize there is much more of a depth than I, I originally thought, um, he's wonderful to work with, he's easy to work with, he understands, he's smart, and I never picked up any of that, he's our, I think that's been a great experience. And I'm glad it happened, because I don't want that to be, we hire so few people from the outside, I don't want that to color my feelings of, he's from the outside, that will teach us again, so I think that's been a really good experience.

As a side note, Castignoli remains a high school principal, and was recently named principal of the year for 2015-2016 in Maverick County School District, which cited his commitment to diversity and inclusion and continuing the expectations for excellence previously set by his predecessor.

Finally, a new assistant principal, Alexa Banks, had spent twenty years in a Northern Florida county not examined as a part of this study or the larger, overarching study. Of those twenty years, Banks noted that the last nine years were spent as an assistant principal in which she served in five different buildings. Unlike Castignoli and Strowman, Banks did not plan to jump counties for a principal position and wished to remain an assistant principal. When asked about her experiences and trajectory, Banks commented that, "I was at a, crossroads in my profession. Um, and, it was, I felt like I had reached, and I know this may sound kind of, reached my ceiling there, I felt like I needed a new experience to reenergize me, because sometimes when you are in a place, it just becomes humdrum and mundane." Banks openly sought out Maverick County School District, due to its reputation as one of the top counties in the state, and accepted a position as a high school assistant principal. Ironically, in Banks's five previous assistant principal roles, they were in elementary school and middle school, and never in high school. Banks was excited about this new challenge, as it gave her the opportunity to learn a new system and re-energize. When asked about her expectations, Banks was excited for the fact that she would have the opportunity to 
be an instructional leader in the school and not siloed in discipline. She commented,

Here, we have deans that deal with discipline. (Laughs!) I said at a meeting this morning, it was like, they were talking about, I'm like, you have to do ESE and 504 because, that was $90 \%$ of my job was discipline. But I had to do it all. And so, to me, that is, that's huge because you spend so much of your time on that, that you, you know, you're trying to be a master of everything, but, but you're a jack of all trades, but, but, I'm going to tell you, in my 9 years as an assistant principal, a bulk of my time was spent on discipline.

A new district and fresh start gave Banks the opportunity to redefine her role as an assistant principal, an opportunity which she believes she never would have received in her previous county.

\section{Valravn County School District - Talent is Talent and Can Come from Anywhere}

Valravn County School District experienced the same need for schoolbased administrators as the Maverick County School District, however, their rationale for creating a district-led succession planning program was slightly different. Unlike Maverick County School District, which experienced attrition and consolidation due to the housing crisis, Valravn stayed consistent in their growth and expansion over the last twenty years, however, experienced shifting demographics throughout their county due to an increase in the population of Hispanic and African-American families living in their district. Valravn's school-based administrator recruitment was targeted on finding talented leadership candidates reflective of this shifting population, and also as a precautionary measure for the impending retirements of many school-based administrators. A total of 24 individuals in leadership roles within the Valravn County School District were interviewed as a part of this study. Many described Valravn as one of the top school districts in the state, and one in which they desired to spend the duration of their career. Because of this, this had led to a different type of impending succession, as an elementary school principal described this as the, "last stand of the old white men," and an aspiring school-based administrator noted that it was "finally time to get some new ideas in the county."

Ironically, the two individuals responsible for the leadership succession programs at Valravn County School District were also preparing for their impending retirements. Matt Balor, the Director of Leadership Pathways, was four months shy of retirement at the time of his interview. He indicated that he was tasked with designing and developing a leadership succession planning program by the Superintendent and the Deputy Superintendent of Instruction, Excellence, and Equity with the purpose of refilling the pool of qualified candidates. Upon Balor's retirement, Naomi Lynch, the Director of Leadership 
Development for Valravn County School District, would assume the position of Director of Leadership Pathways, and the Director of Leadership Development position would be eliminated. Lynch had planned to retire in three years, once she had combined the position and made it manageable for her successor.

When discussing succession planning and hiring school-based administrators with Valravn County School District Superintendent Allen Corbin, Corbin brought attention to the two central administrators (the Director of Leadership Pathways and the Director of Leadership Development) who were responsible for the recruitment, retention, selection, and training and development of school-based administrators. Corbin noted that the school board had supported his creation of the position, stating, "when I started talking about succession, they were, they are frequently, one or all of them are with me at different events, um, always looking for leaders, um, understanding the importance of good leadership, um, we go out and we recognize great leaders." Corbin also noted that he believed that the work of the two central administrators would be sustainable, and his ideal mix between internal hires and external candidates was $90 \%$ internal and $10 \%$ external. When asked if he was comfortable with that position, Corbin commented, "Very comfortable. And I think a couple of years ago when I was a little more desperate, I was looking a little harder. We seem to have more people applying to us, for a variety of reasons, we get a lot, just because of UCF (University of Central Florida), and their kids are starting at the university and they want to be a little bit closer, and I'm like, hey, come on down!" Because of the reputation of the Valravn County School District, Corbin did not appear concerned that his district would have challenges with administrator recruitment in the foreseeable future, and credited his training program in providing the aspiring internal candidates the training they need to be successful school-based administrators.

Matt Balor, the Director of Leadership Pathways, expressed his open-door policy to take anyone and everyone interested in a leadership position to his program. Instead of targeting individuals with leadership abilities or individuals recommended by their building principals, Balor was interested in aspiring school-based administrators who self-selected to be a part of his program. He noted that

It's an open door by invitation. With condition. And the condition is, that if you participate, my expectation is that you will fully and actively participate. I'm not going to go around behind you and say, hey look, you haven't done this activity, I shouldn't have to do that with someone who is aspiring bigger or someone who really wants to be exceptional.

Balor believed there were enough aspiring individuals in Valravn to assume school-based administrator positions without external recruitment. When asked to provide a positive experience of an external hire and a negative experience of an external hire, Balor chose not to answer the question, and instead provided two negative experiences, both of which were recent hires. The first experience concerned a principal that did not fit within the Valravn system or 
within his own building's environment. Balor described the situation as follows:

And that was at a time that they needed to break the mold, um, and, um, I made a terrible hire, um, a gentleman out of Orange County who I hired to be a Middle School Reading Coordinator. This guy just presented and had the highest accolades in Orange County, and I thought, I could get this guy, and get him over here, and he was doing great things in the school, and he carried himself, you know, and said, man, I'm gonna get this guy, he got over here, he couldn't get along with anybody, from the principal at the middle school or at the district-level, he couldn't get along with people, he was arrogant.

In addition, Balor spoke about a recent hire that impacted the morale of his current school principals. He stated, "I can tell you, we've had one outside hire recently, that it's sort of unsettled a lot of people, about $90 \%$ of our principals are unsettled by that." Balor truly believed that his best leaders can, and would, eventually come from within.

The Director of Leadership Development, Naomi Lynch, also expressed the importance of internal promotion as opposed to external hires. She mentioned that her vision for Valravn County School District was more along the lines of horizontal cross-training, where a middle school principal could be moved into an elementary or high school principalship and still be effective. She expressed that good leaders can be good leaders "regardless of their grade level" and hoped for a "vertical system where people can move between grade levels." Lynch also expressed optimism with her current group of principals. She stated

we sort of have this very young group of principals, that are, you know, just starting their principal careers, and you know, I think something that just kind of, I'm thinking about down the line is, now that we've had this big blast, now we're going to have another dry period where there aren't going to be opportunities for people, so how do we keep our really great people here so they don't leave and go somewhere else and give them opportunities for leadership and building their capacities so they see a way to stay.

Lynch was confident in her current group of both principals and assistant principals, and believed that retention strategies job satisfaction should be Valravn's focus.

When speaking with externally hired principals, all but one currently practicing principal expressed support, appreciation, and general happiness of their decision to apply to the Valravn County School District. One elementary principal commented on her experience as an outside hire as extremely positive, stating,

Bringing in an outsider who there's no preconceived notions with, you know, because they get on the phone, you know how teachers are, you know how parents are, I'm getting a principal from so and so, tell me about, and they all 
have friends, they all network, exactly, so I think that was in my favor, because they knew nothing about me.

A middle school principal who had just entered Valravn from Gemini expressed gratitude that she had left the "brick wall" that was Gemini County School District and entered a county like Valravn who "put their leadership team first." However, she did comment on the challenges of being an out-of-county hire:

so it's very hard coming from another county, and I've said this to my faculty, because I've changed schools before, and when you change schools, the faculty go and call their friend, they didn't have anybody to call, I'll stand on my reputation, right, so, it was like, oh gosh, alright, and then you're different anyway, so it's been a challenge that way, so I just look at it like, they're going to have to trust, and I'm going to have to build relationships, and some left, and I got new ones, and some are here, and so that's been hard, um, and if you're somebody who's been in the same building for five years and you're a principal coming in, you better check yourself at the door, it's going to be hard.

Despite their positive experiences, one school-based administrator in particular was not pleased with her transition to Valravn County School District. Bailey Martinez had previously served as a turnaround principal in a North Florida County not covered in this study or the larger study, and had a reputation for working with more challenging student populations. Martinez expressed burnout and stress of having to be the person that "fixes" everything in her previous county, and was hoping to come to Valravn to rejuvenate and rediscover her passion for school administration. When describing her experience with the interview process, Martinez stated that, "There were two positions and I asked what schools they were, both A schools, and a B school well great I thought I could interview and get out of the turn around." However, after her first year serving as a principal in a high-performing elementary school, Martinez was placed in an "F" School, and when asked about her placement, she stated, "So, am I happy, no. I was actually contacted by 'North Florida County' in July end of June, beginning of July to come back, and to be honest with you it was a tough struggle. To not go back. Because that's my home I still have my house there. So it was a tough struggle for me not to go back." Martinez also indicated that she was struggling to learn the systems that were in place for Valravn County School District, stating that:

Um, not knowing some of the systems that are in place here. That's been a real struggle. Even with the teachers here, because if they come and ask me a question and I don't really know so I will give you an example. They wanted to know a question about, they have a leak in their ceiling. That's the example. I don't know who to contact. I knew who to contact in 'Northern Florida County.' It takes a few minutes because I have to get back to them I 
have to call the right person, the I am able to say ok I will have it taken care of for you today. I knew the time frame of a teacher request and how long it took and things of that nature. That's been a little bit of a struggle for me, not knowing some of their contact people.

Ironically, Martinez remains in the Valravn County School District, despite her dissatisfaction for the county at the time of the interview. She is now the principal of a high-performing elementary school in the county, and is no longer a turnaround principal.

\section{Discussion}

From the findings discussed in the previous section, we acknowledge three challenges and three opportunities associated with the concept of internal vs. external school-based administrator hires.

\section{Challenge \#1 - Resentment from Internal Candidates}

Leaders are by their nature, proactive and mission driven. Whenever an opening occurs in a school district, there will be internal candidates who have trained for, and seek out the opportunity for professional growth and promotion. Many of these individuals will feel that they have paid their dues, waited for their turn and know that they are ready and deserving of the promotion to the principalship. It can be a shock to these candidates to discover that, not only did they not get the job, but none of their "in district" colleagues got the job either. It is a natural reaction for these individuals to feel somehow cheated by the district leadership. It is only natural for these candidates to wonder whether they are truly valued by the institution's leaders. The confusion and resentment that can build as a result of these feelings is one of the biggest threats to both the new principal coming into the system as an external hire, and to the district leadership's ability to maintain a positive and proactive leadership mindset for those individuals who did not get the position. There are both proactive and reactive steps that district leaders should take to minimize these feelings of resentment. In our data, two school-based administrators, one from Maverick County School District and one from Valravn County School District identified this resentment as a challenge. The school-based administrator from Maverick specially noted that she had to "go into these groups and kind of infiltrate and talk to teachers and the ones that who were not on board or negative" in order to ensure her success.

\section{Challenge \#2 - Central Administration's Willingness to Hire Externally}

Senior leadership needs to contextualize the process and reasons for a balance between internal and external hires. One proactive and crucial step district leaders, who are committed to finding a balance between internal and external hiring, need 
to take is to share and discuss the philosophy and benefits behind having a balance in hiring practices. Everyone can and should know that the district values internal hiring, but also values the growth that can occur by having some external hiring as well. If everyone understands that some external hiring is a strategic initiative, well thought out and implemented, and not a slight against the talent pool inside the district, there is more likelihood that internal candidates will recognize that an external hire is not a statement about the trust the district has in its own employees, but part of a well-articulated strategic plan. In this study, there was a clear difference of opinion from central administration as to whether or not to hire external candidates. The Maverick County School District Superintendent viewed hiring two of his last three principals externally as a "big problem," whereas the Director of Leadership Pathways from the Valravn County School District believed that it was important to consider external candidates as a way to keep ideas fresh and to keep current aspiring administrators who may believe they have an advantage "on their toes." It should also be noted that the Director of Leadership Pathways was also responsible for the addition of an external aspiring administrator from another school district in their internal succession planning program. Additionally, the superintendent from Valravn County School District encouraged the recruitment of external candidates as "healthy for me to bring people from other districts to learn different practices."

\section{Challenge \#3 - Understanding the Culture and Climate of the New District}

External candidates need to learn the culture, climate, and the overall processes of their new organization. Some induction support is needed. One of the natural challenges is getting up to speed on the multitude of systems and personnel that a new external hire had come to take for granted in their previous district. They no longer instinctively know who to call on any particular issue. They no longer know all of the HR procedures, or finance procedures for the district. All of these management issues are of course, learned issues, but they take some time. Having a mentor at the district, who can help the external hire navigate the system is very valuable and beneficial. A consideration is to build a support structure of job-alike colleagues. New external hires may want to connect with other secondary school principals who are held in high regard by the district and their school communities. This allows them to introduce themselves, and share their background, goals, and hope for their new position and also learn the culture of the district from experienced administrators. In this study, a new school-based administrator from outside the county was hired for the Valravn County School District to be a turnaround principal in a very low-performing elementary school. While she felt confident in her abilities, she stressed the challenges of hitting the ground running in a challenging school setting. Another example from the Valravn County School District was a new middle school principal who was hired to be a principal of a high-performing middle school. She did not feel the pressures to the level the other principal did, and expressed that she had the time to learn the culture and the climate of the district. 


\section{Opportunity \#1 - New Leaders Bring New Perspectives}

New leaders bring new ideas and experiences from outside the organization. Hiring a new leader can present an external view of the school's culture and climate, especially if the culture and climate are a concern for the school district. When hiring a school principal from outside the district, the new set of eyes that will "see the school" has the potential to be much more impactful than someone already acculturated with the organizations practices. In this case, the district is getting a new set of eyes and perspectives about the school's culture and climate on a full-time basis. The potential for an external principal to assess all aspects of the school is extremely significant and valuable. Whether it is the professional dispositions of the faculty and staff, the professional development needed in specific areas, the unrecognized strengths and potential of the organization as a whole, the relationships between the school and external stakeholders; the ability for an external principal to see the school through the lens of someone from outside the organization, but who has expertise in school leadership and pedagogy, is clearly one of the, if not the biggest strength an external hire brings to the district.

\section{Opportunity \#2 - An External Candidate's First Impression comes in a Leadership Role}

New leaders are not tied down by previous relationships in the organization. Hiring an external candidate enables a fresh start, not only for the leader, but also for the entire organization. It is human nature to form opinions about the people you work with and interact with. These opinions often lead to leadership behaviors that limit the potential for individuals in the organization, or even external stakeholders, to reinvent themselves and reach their potential. A principal from outside the organization, however, will see each employee and stakeholder with fresh eyes. The opportunity for employees who have been marginalized or who were not performing up to their capacity, to reinvent themselves with a new leadership team is real and should be taken advantage of by the external hire. The same opportunity exists for the students in the school and how they are viewed by the principal. There is only one real opportunity to truly make a first impression on the organization and its stakeholders. External hires have a unique opportunity to make that impression.

\section{Opportunity \#3 - New Connections to Make the Organization Stronger}

New leaders bring connections and can help build bridges to support systems and stakeholders not currently utilized by the school or district. We live in an age where no school leader can succeed on their own. It takes a team to lead effectively. It also takes many external partners to support that leadership team. By their very nature, external hires have contacts and partnerships from outside the district. Often these contacts and business or education partners can also bring those resources to the new school and district. These resources may be new business 
partnerships, new field study or internship opportunities for students, or even new university contacts. This, in itself, increases the capacity of the organization. It is not just the experiences that external candidates bring to the table, it is also the partnerships that they have cultivated over the years.

\section{Conclusion}

Should the shortage of candidates aspiring for school-based administrator positions continue to exist across the United States, deliberate, internal succession planning programs, similar to the ones established in the two school districts presented in this study, will be one method of preparing future school-based administrators. However, despite these programs designed to reward aspiring internal candidates, there will always be external candidates seeking school-based administrative positions outside of their current school district. Whether it be an inability to advance in their current county school district, believing that a better fit may exist elsewhere, or a number of other factors, either personal or professional, credentialed candidates may desire to explore external options. Central administrators responsible for those hiring decisions should consider all candidates, and not just candidates that come from their internal county-based programs.

\section{References}

Augustine, C. H., Gonzalez, G., Ikemoto, G. S., Russell, J., \& Zellman, G. L. (2009). Improving school leadership: The promise of cohesive leadership systems. Rand Corporation.

Burgess, W. (2016, October 3). Why companies overlook great internal candidates. Retrieved from http://bit.ly/2dLp26m.

Caplan, R. D. (1987). Person-environment fit theory and organizations: Commensurate dimensions, time perspectives, and mechanisms. Journal of Vocational behavior, 31(3), 248-267.

Chan, W. (1996). External recruitment versus internal promotion. Journal of Labor Economics, 14(4), 555-570.

Chen, K. P. (2005). External recruitment as an incentive device. Journal of Labor Economics, 23(2), 259-277.

Dollard, M. F., \& Metzer, J. C. (1999). Psychological research, practice, and production: The occupational stress problem. International Journal of Stress Management, 6(4), 241-253.

Dowdy, L. (2015, September 15). Job hopping can boost your career if you do it right. Retrieved from http://cnb.cx/1ie4ArG.

Duke, D. L. (1988). Why principals consider quitting. The Phi Delta Kappan, 70(4), 308312.

Edwards, J. R., Caplan, R. D., \& Van Harrison, R. (1998). Person-environment fit theory: Conceptual foundations, empirical evidence, and directions for future research. In C. L. Cooper (Ed.), Theories of organizational stress (pp. 29-67). New York: Oxford University Press. 
Fauske, J. R., \& Ogawa, R. T. (1987). Detachment, fear, and expectation: A faculty's response to the impending succession of its principal. Educational Administration Quarterly, 23(2), 23-44.

French, J. R., Rodgers, W., \& Cobb, S. (1974). Adjustment as person-environment fit. In G. V. Coelho, D. A. Hamburg, \& J. E. Adams (Eds.), Coping and adaptation, (pp. 316-333). New York: Basic Books.

Kanter, R. M. (1989). The new managerial work. Harvard Business Review, 67(6), 85-92.

LaRocco, J. M., House, J. S., \& French Jr, J. R. (1980). Social support, occupational stress, and health. Journal of Health and Social Behavior, 202-218.

McAdams, R. P. (1998). Who'll Run the Schools? American School Board Journal, 185(8), 37-39.

Meyer, J. W., \& Rowan, B. (1977). Institutionalized organizations: Formal structure as myth and ceremony. American journal of sociology, 83, 340-363.

Miles, M. B., \& Huberman, A. M. (1994). Qualitative data analysis: An expanded sourcebook. Thousand Oaks, CA: Sage.

Moser, K. (2005). Recruitment sources and post-hire outcomes: The mediating role of unmet expectations. International Journal of Selection and Assessment, 13(3), 188197.

Normore, A. H. (2004). Recruitment and Selection: Meeting the Leadership Shortage in One Large Canadian School District. Canadian Journal of Educational Administration and Policy, 30, 1-15.

Ostroff, C., \& Rothausen, T. J. (1997). The moderating effect of tenure in personenvironment fit: a field study in educational organizations. Journal of Occupational and Organizational Psychology, 70(2), 173-188.

Papa, F. C., Lankford, H., \& Wyckoff, J. (2002). The attributes and career paths of principals: Implications for improving policy. Teacher Policy Research Center.

Patton, M. Q. (2002). Qualitative research and evaluation methods. $3^{\text {rd }}$ Ed. Thousand Oaks, CA: Sage.

Pijanowski, J. C., Hewitt, P. M., \& Brady, K. P. (2009). Superintendents' perceptions of the principal shortage. NASSP Bulletin, 93(2), 85-95.

Rogers, E. (1962). Diffusion of Innovations. New York: The Free Press of Glencoe.

Roza, M. (2003). A matter of definition: Is there truly a shortage of school principals? Center on Reinventing Public Education, University of Washington.

Russell, J. L., \& Sabina, L. L. (2014). Planning for Principal Succession: A conceptual framework for research and practice. Journal of School Leadership, 24(4), 599-634.

Sabina, L. L. (2014). Factors influencing elements of stress and autonomy and control among school administrators (Doctoral dissertation). Retrieved from http://bit.ly/ 2nWq3u2.

Schneider, M., \& Somers, M. (2006). Organizations as complex adaptive systems: Implications of complexity theory for leadership research. The Leadership Quarterly, 17(4), 351-365.

Silva, P. (2006). Effects of disposition on hospitality employee job satisfaction and commitment. International Journal of Contemporary Hospitality Management, 18(4), 317-328.

Stake, R. (1995). The art of case study research. Thousand Oaks, CA: Sage Publishing.

Strauss, A. \& Corbin, J. (1998). Basics of qualitative research. Thousand Oaks, CA: Sage Publishing.

Weick, K. E. (1976). Educational organizations as loosely coupled systems. Administrative Science Quarterly, 21, 1-19.

Winter, P. A., Rinehart, J. S., \& Muñoz, M. A. (2002). Principal recruitment: An empirical evaluation of a school district's internal pool of principal certified personnel. Journal 
of Personnel Evaluation in Education, 16(2), 129-141.

Yin, R. (1994). Case study research: Design and methods. Thousand Oaks, CA: Sage Publishing. 
